\title{
Trends in Hip Fracture Incidence, Length of Hospital Stay, and 30-Day Mortality in Sweden from 1998-2017: A Nationwide Cohort Study
}

\author{
Peter Nordström ${ }^{1}$ (D) Jonathan Bergman ${ }^{1}$ (D) $\cdot$ Marcel Ballin $^{1,2}$ (D) $\cdot$ Anna Nordström ${ }^{2,3}$ (D)
}

Received: 30 November 2021 / Accepted: 25 January 2022 / Published online: 15 February 2022

(c) The Author(s) 2022

\begin{abstract}
In this nationwide cohort study, we investigated trends in hip fracture incidence, hospital length of stay (LOS), and 30-day mortality after admission in Sweden. The cohort included all individuals in Sweden aged $\geq 50$ years with a first hip fracture diagnosis during 1998-2017 $(N=313,761)$. The outcomes were hip fracture incidence and 30-day mortality. The results showed that the incidence of hip fracture decreased from 79.2 to 46.7/10,000 population in women and from 35.7 to $26.5 / 10,000$ population in men. In contrast, 30 -day mortality increased from $4.3 \%$ to $6.2 \%$ in women $(P<0.001)$ and from $8.4 \%$ to $11.1 \%$ in men $(P<0.001)$. Strong risk factors $\left(P<1 \times 10^{-25}\right.$ for all $)$ for 30 -day mortality were older age, male sex, and shorter LOS. From 1998 to 2017, LOS decreased by on average 4 days and was shorter in both male and female aged $\geq 90$ years compared to those aged $80-89$ ( $P<0.001$ for comparisons). In conclusion, despite population aging, hip fracture incidence in Sweden has decreased over the last 20 years. However, short-term mortality has increased, which to some extent may partly be explained by the fact that LOS has decreased without being adapted to important risk factors.
\end{abstract}

Keywords Fracture $\cdot$ Incidence $\cdot$ Mortality $\cdot$ Epidemiology $\cdot$ Risk factors

\section{Introduction}

In 2000 , an estimated nine million fragility fractures occurred worldwide [1], with adverse consequences including chronic pain [2], disability, and premature death [3, 4]. The hip fracture is the most devastating type of fracture both for the individual and the society [5], with nationwide studies and meta-analyses showing that about $25 \%$ of hip fracture patients die within a year of the event $[4,6,7]$. In addition, among those that survive, recovery to pre-fracture functional level is often unsuccessful [8].

From the 1950s to the mid-1990s, the incidence of hip fracture increased in many countries [9-12], a trend that coincided with population aging [13]. Despite continued

Peter Nordström

peter.nordstrom@umu.se

1 Department of Community Medicine and Rehabilitation, Unit of Geriatric Medicine, Umeå University, 90187 Umeå, Sweden

2 Department of Public Health and Clinical Medicine, Section of Sustainable Health, Umeå University, Umeå, Sweden

3 School of Sport Sciences, UiT the Arctic University of Norway, Troms $\varnothing$, Norway population aging, there are studies suggesting that the incidence of hip fractures has leveled off $[14,15]$, or even decreased according to the most recent studies [16-18], although the cause of this is uncertain $[17,19]$. There also seems to be substantial variation when comparing these trends in low-, middle-, and high-income countries [20]. Given these trends and variations, contemporary nationwide studies spanning over decades would be of interest, exploring also possible reasons for a decreasing incidence.

In addition to the public health burden of hip fractures, these fractures are considered a good measure of the quality of healthcare [21], where inpatient length of stay (LOS) may not only be adapted to patient demands, but also influenced by economic constraints in health care. A previous study from Sweden reported declining hip fracture incidence during the last two decades but lack of improvement in mortality rates [18]. However, neither time trends in LOS nor the influence of LOS on short-term mortality were investigated [18]. In an earlier study, we showed that in hip fracture patients, shorter LOS was associated with increased risk of death after discharge [6]. These results were confirmed in a recent study investigating hip fracture patients with dementia [22]. By implication, it could be hypothesized that efforts to reduce LOS related to economic constraints may have 
a negative influence on absolute short-term mortality over time. In this study, we, therefore, investigated the trends in hip fracture incidence, LOS, and 30-day mortality after hospitalization for hip fracture in the Swedish population during 1998-2017.

\section{Material and Methods}

\section{Study Population}

For the present study, we included all individuals in Sweden with a first hip fracture at an age of at least 50 years in 1998 until 2017. Hip fractures were tracked using the Swedish National Patient Register (NPR), controlled by the National Board of Health and Welfare (www.socialstyrelsen.se), using the International Classification of Diseases, 10th revision, (ICD-10) codes S720 (fractures of the femoral neck), S721 (fractures of the trochanter) and S722 (subtrochanteric hip fractures). For the fractures of the femoral neck and trochanter, we also obtained information about the type of operation (procedure codes NFB [operation with prosthesis], NFJ [operation with internal fixation]). Diagnoses in inpatient health care have been collected in the NPR since the late 1960s, with complete coverage since 1987 . To estimate the yearly incidence of hip fractures, the size of the Swedish population above 50 years of age in 1998-2017 was obtained from Statistics Sweden [23].

\section{Covariates}

Covariates were selected based on known associations with hip fractures or death. Diagnoses were obtained from the NPR using the following ICD-10 codes: I21 (myocardial infarction), I61-I64 (stroke), I20 (angina pectoris), E10, E11 (diabetes mellitus), N17-N19 (kidney failure), J43, J44 (chronic obstructive pulmonary disease, COPD), F10 (alcohol dependency), F32-F33 (depression), C (cancer), and F00-F03 (dementia). We included only diagnoses set within one year prior to the fracture because the NPR switched to ICD-10 codes in 1997, so only one year of ICD-10 codes was available for hip fracture patients in 1998 (the first year of the study).

Socioeconomic data, including disposable income, early retirement pension, and marital status (married, never married, divorced, or widowed), were obtained from Statistics Sweden for each patient in the year before the fracture occurred. The data were missing in $0.1 \%$ of the patients. The Swedish Prescribed Drug Register was used to collect data on all prescriptions for bone-specific agents (anatomical therapeutic classification code, M05B) dispensed at pharmacies in Sweden since July 2005. Specifically, we tracked use of bone-specific agents within the past year in patients that sustained hip fractures in 2007 and later. Finally, hospital LOS was estimated from the NPR, where the date of admission and discharge were recorded. If a patient was transferred from one ward to another on the same date, the separate LOS were summed. The present study was approved by the Swedish Ethical Review Authority, number 2019-04765, and by the National Board of Health and Welfare, and by Statistics Sweden.

\section{Statistics}

Data in the present study were presented as means and standard deviations, unless stated otherwise. Differences between two groups were investigated using a Student's t-test for independent samples. The mean change in hip fracture incidence per year was estimated using linear regression with autoregressive moving average (ARMA) errors, to account for possible dependency of errors. To estimate mean percentage change in incidence, we used the same model but applied the natural logarithmic transformation to hip fracture incidence (the outcome). The order of the ARMA model was selected as the minimum order for which there was no significant autocorrelation or partial autocorrelation. Separate models were run for men and women and each age group.

The risk of death within 30 days of admission was investigated using Cox regression. LOS was entered as a timevarying variable (value 1 on the day of hospitalization, 2 on the second day of hospitalization, and so on, until the day of discharge, after which it was constant). The Cox model was adjusted for age, sex, income, early retirement pension, marital status (4 categories), type of fracture (3 categories), type of operation (6 categories) and 10 different diagnoses. In a sensitivity analysis, individuals were included with a LOS of 10 days or less and alive at discharge. The outcome in this analysis was death from day 11 to 30 after admission and LOS was included as a non-time dependent covariate. Data on mortality were obtained from the Swedish Cause of Death register, which is complete since 1952. [24] All analyses were performed using Stata MP, version 16.1 for Mac (StataCorp, College Station, TX 77845, USA) and RStudio ( $\mathrm{R}$, version 4.0.3). $\mathrm{P}$ values of less than 0.05 and $95 \%$ confidence intervals $(\mathrm{CI})$ not including one was considered significant.

\section{Results}

\section{Study Cohort}

From 1998 to 2017, Sweden's population aged 50 or older increased from 3.13 million (33.5\% of the total population) to 3.85 million (38.4\% of the total population) individuals. During this period, a total of 313,761 individuals 
were diagnosed with a first hip fracture. Some of the variables describing baseline characteristics of the hip fracture patients changed between 1998 and 2017 (Table 1, Supplementary Table 1). Inpatient LOS decreased from a mean of about 14 days in 1998 to 10 days in $2017(P<0.001)$. In terms of operation techniques, there was a substantial increase in patients operated with prosthesis after a femoral neck fracture. The proportions of patients with a recent myocardial infarction, stroke, or angina pectoris at the time of the hip fracture decreased during follow-up. In 2007, 1.6\%

Table 1 Basal characteristics of the study cohort in $1998(N=18,534)$ and in $2017(N=14,188)$

\begin{tabular}{|c|c|c|}
\hline Variables & 1998 & 2017 \\
\hline Age, years & $81.3 \pm 9.0$ & $81.9 \pm 9.8$ \\
\hline Female sex (\%) & 72 & 65 \\
\hline Income (1000 Swedish krona) & $95 \pm 60$ & $190 \pm 389$ \\
\hline Early retirement pension (\%) & 3.1 & 2.7 \\
\hline Missing, \% & 0.1 & 0.1 \\
\hline \multicolumn{3}{|l|}{ Marital status, $\%$} \\
\hline -Widow/widower & 48.6 & 38.9 \\
\hline -Married & 30.3 & 33.6 \\
\hline -Not married & 11.0 & 10.6 \\
\hline -Divorced & 10.0 & 16.7 \\
\hline Missing, \% & 0.1 & 0.1 \\
\hline Length of stay, days (mean $\pm S D$ ) & $14.8 \pm 14.4$ & $10.2 \pm 7.5$ \\
\hline \multicolumn{3}{|l|}{ Type of fracture and operation } \\
\hline \multicolumn{3}{|l|}{ Collum femoris fracture (\%) } \\
\hline -Operated with prosthesis & 4.4 & 32.6 \\
\hline -Operated with nails & 18.6 & 7.4 \\
\hline -Operated with screws & 16.5 & 6.8 \\
\hline -Operated with other technique/unknown & 14.9 & 7.4 \\
\hline \multicolumn{3}{|l|}{ Trochanteric fracture $(\%)$} \\
\hline -Operated with intermedullary nail & 1.4 & 19.3 \\
\hline -Operated with combined technique & 26.6 & 12.8 \\
\hline -Operated with other technique/unknown & 10.6 & 6.1 \\
\hline Subtrochanteric fracture (\%) & 7.0 & 7.6 \\
\hline \multicolumn{3}{|l|}{ Cause of fracture $(\%)$} \\
\hline -Snow or ice & 3.6 & 3.3 \\
\hline -Inside & 71.3 & 57.1 \\
\hline \multicolumn{3}{|l|}{ Debut of diagnoses the last year, $\%$} \\
\hline -Myocardial infarction & 1.2 & 0.7 \\
\hline -Stroke & 2.9 & 1.6 \\
\hline -Angina pectoris & 2.2 & 0.4 \\
\hline -Diabetes & 2.7 & 1.3 \\
\hline -Kidney failure & 0.6 & 1.5 \\
\hline -Obstructive pulmonary disease & 1.0 & 0.7 \\
\hline -Alcohol dependency & 3.0 & 2.3 \\
\hline -Depression & 1.1 & 0.5 \\
\hline -Cancer & 1.8 & 2.2 \\
\hline - Dementia & 2.8 & 2.4 \\
\hline
\end{tabular}

of the patients were prescribed a bone-specific drug in the year before the fracture compared to $1.2 \%$ in 2017 .

\section{Incidence and Total Number of Hip Fractures, 1998-2017}

The incidence of hip fractures decreased from 79.2 to 46.7 per 10,000 population in women and from 35.7 to 26.5 per 10,000 population in men, equal to a mean decrease of 1.4 (95\% CI, 1.6-1.3; $P<0.001)$ and 0.4 (95\% CI, 0.5-0.3; $P<0.001)$ cases per year and 10,000 population, in women and men, respectively (Fig. 1). A significant relative risk reduction was observed in all age groups, but the absolute risk reduction was higher in older age groups (Table 2). Furthermore, the total number of hip fractures decreased between 1998 and 2017, from 13,340 to 9266 cases in women, and from 5194 to 4922 fractures in men (Supplementary Fig. S1).

\section{A 30-Day Mortality After Hip Fracture, 1998-2017}

Between 1998 and 2017,30-day mortality after hip fracture increased from $4.3 \%$ to $6.2 \%$ in women and from $8.4 \%$ to $11.1 \%$ in men (Fig. 2). In unadjusted analyses, this was equal to a mean increase of $1.9 \%$ (Hazard ratio, [HR], 1.019, $95 \%$ CI, 1.016-1.022, $P<0.001)$ and $1.1 \%$ per year $(\mathrm{HR}, 1.011$, 95\% CI, 1.007-1.014 $P<0.001$ ), in women and men, respectively. In men aged 90 and above, the absolute risk of 30-day mortality increased by $8.1 \%$ and the relative risk increased by $53 \%$, from 1998 to 2017, which was higher than for any other age group of women or men (Fig. 2). In the total cohort, the strongest risk factors $\left(P<1 \times 10^{-25}\right.$ for all $)$ for 30-day mortality in the model included age (HR, 1.08, 95\% CI, 1.08-1.09, per year higher age), male sex (HR, 2.34, 95\% CI, 2.27-2.40), and LOS (HR, 0.96, 95\% CI, 0.96-0.96 per day longer LOS). Other strong risk factors included type of fracture and operation, and diagnosis of kidney failure (HR, 1.80, 95\% CI, 1.63-1.98), myocardial infarction (HR, 1.70, 95\% CI, 1.55-1.86), COPD (HR, 2.05, 95\% CI, 1.84-2.28) and cancer (HR, 1.63, 95\% CI, 1.52-1.76) within one year prior to the hip fracture.

\section{LOS After Hip Fracture}

LOS was not adapted to risk factors for 30-day mortality, such as male sex or older age (Fig. 3). Specifically, mean LOS was similar in men and women during the study period, and it was longer in patients aged 80-89 years than in patients aged 90 years or above $(13.0 \pm 11.0$ vs. $12.3 \pm 10.2$ days in men, $P<0.001$ for comparison; $13.3 \pm 11.3$ days vs. $12.8 \pm 10.3$ days in women, $P<0.001$ for comparison). In comparison, 30-day mortality was lower in patients aged $80-89$ years than in patients aged 90 years 


\section{(A) Women}

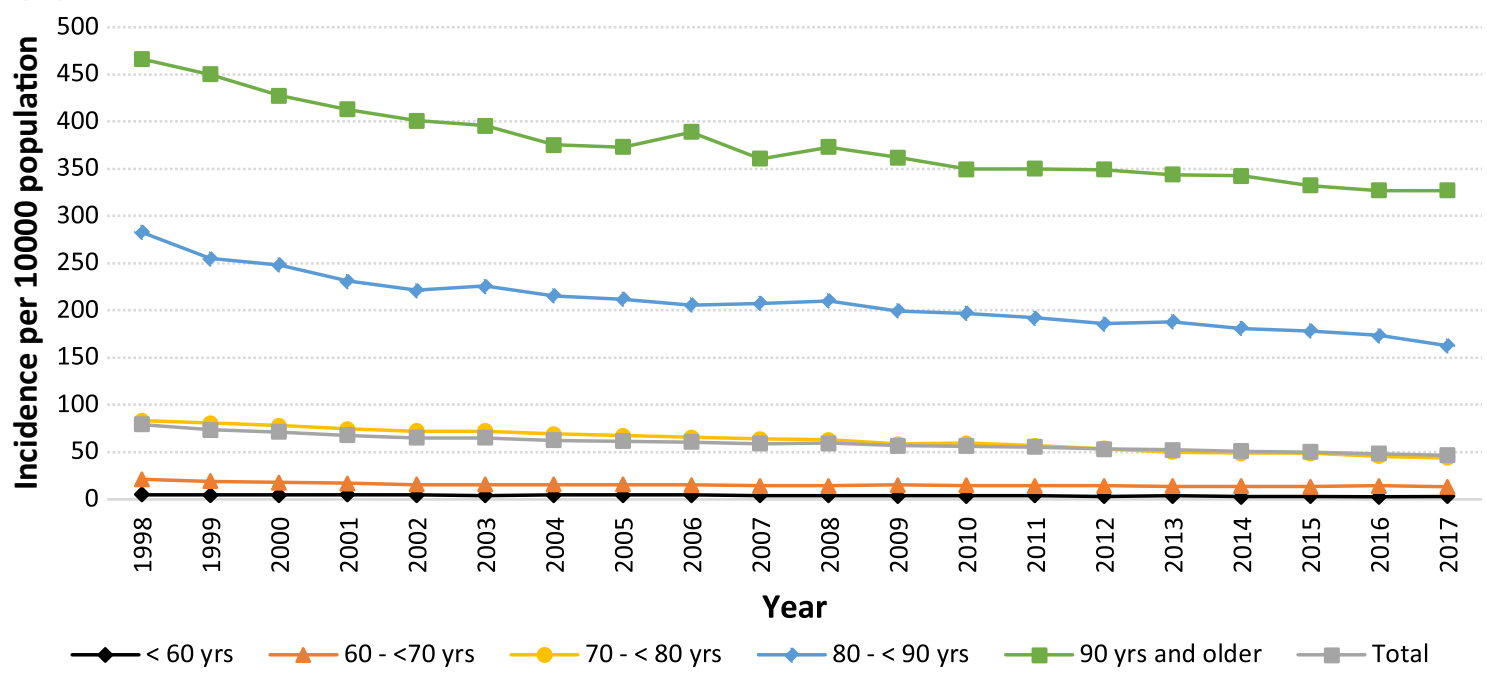

(B) Men

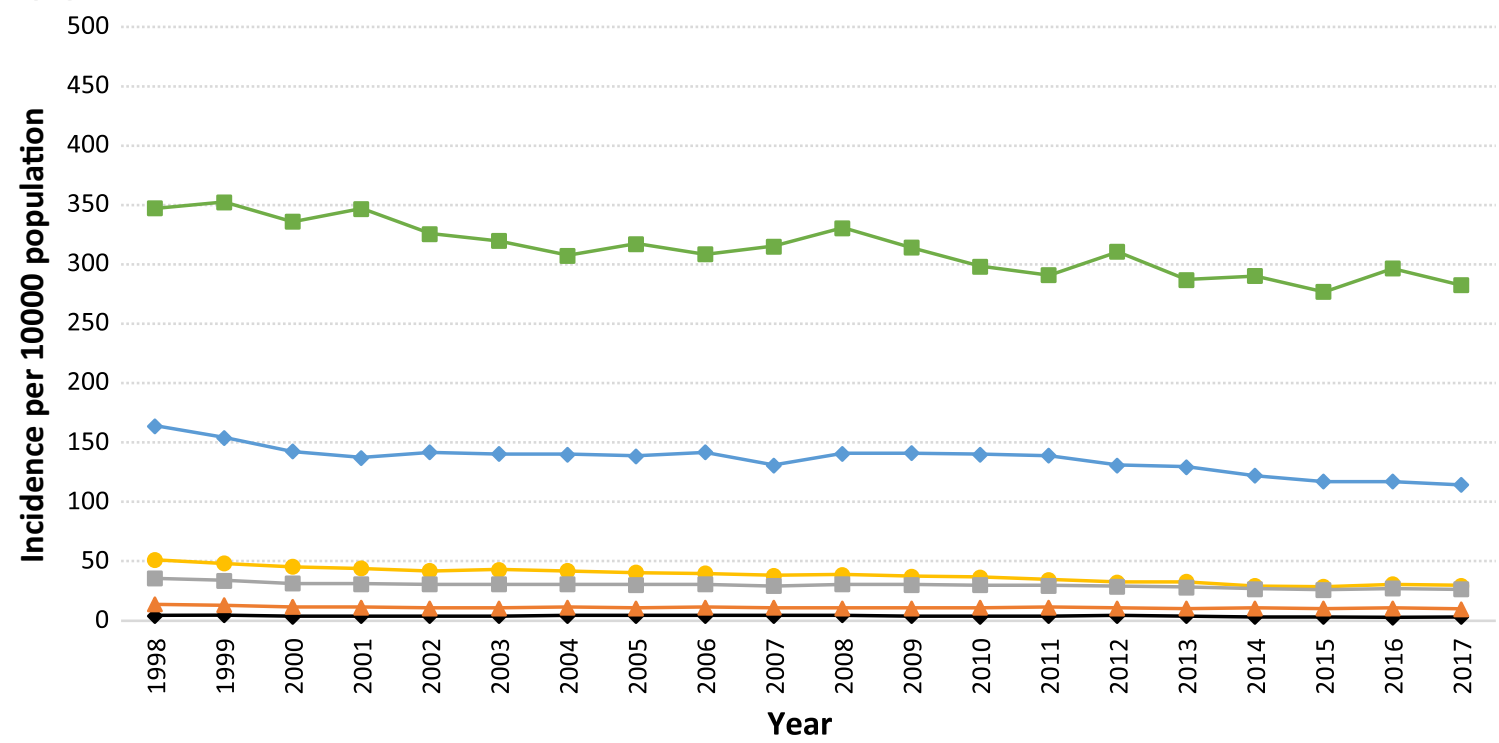

Fig. 1 Incidence of hip fractures from 1998 to 2017 in Swedish women (A) and in men (B) in total and according to age groups

Table 2 Mean change in yearly hip fracture incidence by age and sex

\begin{tabular}{llllll}
\hline & \multicolumn{2}{l}{$\begin{array}{l}\text { Mean change in annual cases/10,000 popula- } \\
\text { tion }(95 \% \mathrm{CI})\end{array}$} & & \multicolumn{2}{l}{ Mean percentage change/year $(95 \% \mathrm{CI})$} \\
\cline { 2 - 3 } \cline { 5 - 6 } Age group & Men & Women & & Men & Women \\
\hline$<60$ & $-0.1(-0.1,-0.0)$ & $-0.1(-0.1,-0.1)$ & & $-1.5(-2.3,-0.7)$ & $-2.4(-2.9,-1.9)$ \\
$60-69$ & $-0.1(-0.2,-0.1)$ & $-0.3(-0.4,-0.2)$ & & $-0.9(-1.3,-0.6)$ & $-1.9(-2.5,-1.4)$ \\
$70-79$ & $-1.1(-1.2,-1.0)$ & $-2.0(-2.1,-1.9)$ & & $-2.8(-3.0,-2.5)$ & $-3.2(-3.4,-3.0)$ \\
$80-89$ & $-1.9(-2.4,-1.3)$ & $-4.8(-5.4,-4.1)$ & & $-1.4(-1.8,-1.0)$ & $-2.2(-2.5,-2.0)$ \\
$\geq 90$ & $-3.4(-4.1,-2.6)$ & $-6.5(-7.7,-5.3)$ & $-1.1(-1.3,-0.8)$ & $-1.7(-1.9,-1.4)$ \\
\hline
\end{tabular}

or above (13.2\% vs. $22.9 \%$ in men, $P<0.001$ for comparison; $5.6 \%$ vs. $11.3 \%$ in women, $\mathrm{P}<0.001$ for comparison). LOS was rather similar in patients with diagnoses that showed that the strongest association with 30-day mortality. Thus, in unadjusted analyses, mean LOS by comorbidity was $13.3 \pm 11.2$ days (kidney failure), $13.6 \pm 11.4$ days 


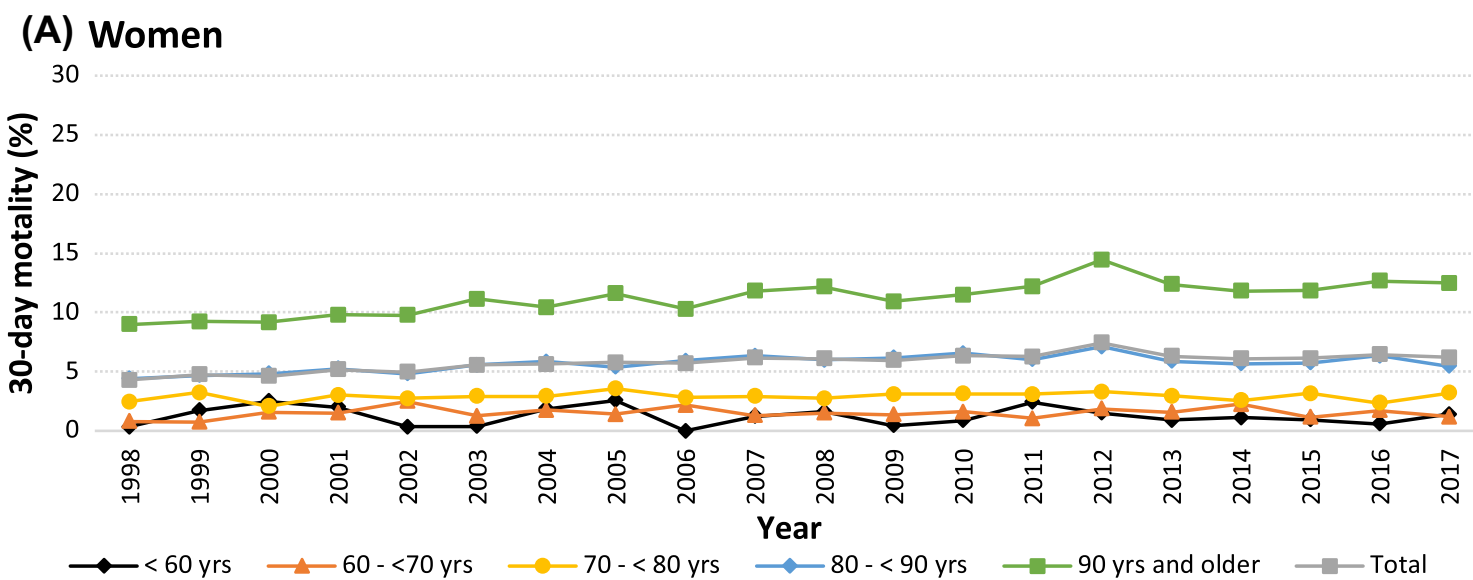

(B) Men

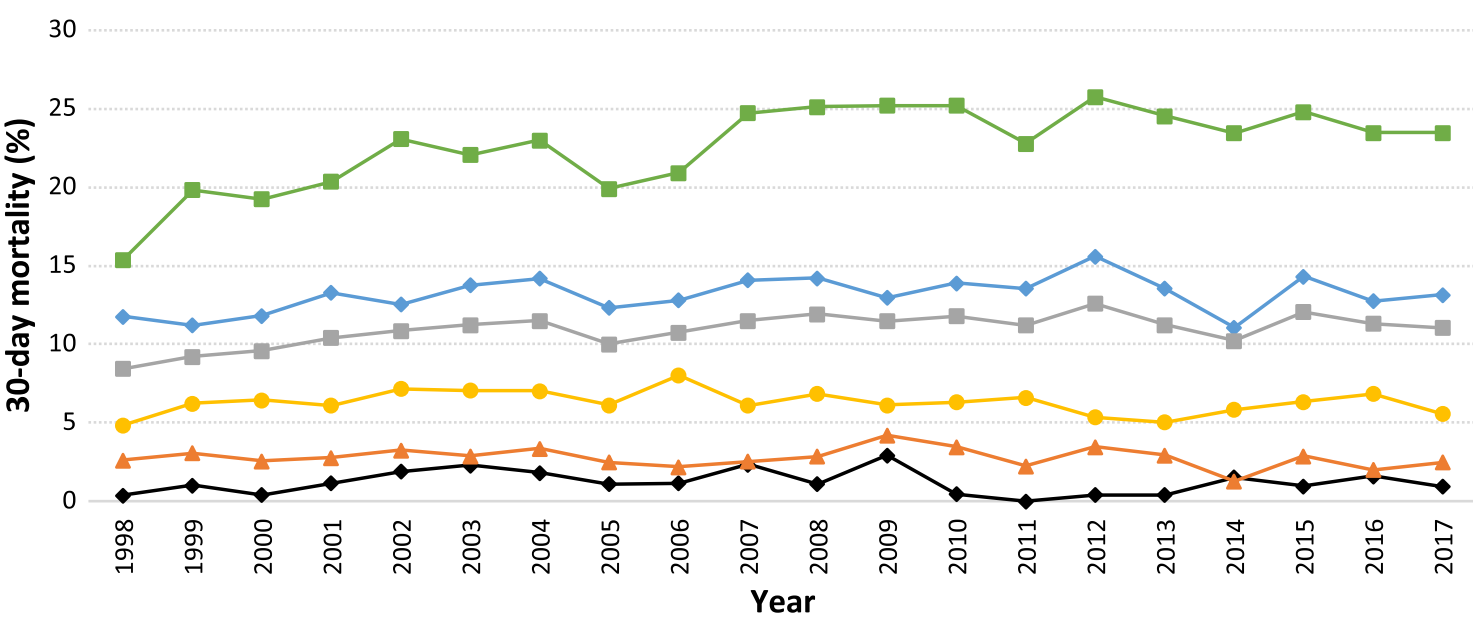

Fig. 2 Risk of death within 30 days of admission from 1998 to 2017 in Swedish women (A) and in men (B) in total and according to age groups

(myocardial infarction), $13.8 \pm 12.2$ days (stroke) and $13.3 \pm 11.9$ days $(\mathrm{COPD})$, compared to $12.5 \pm 10.7$ days in the total cohort.

In a sensitivity analysis, only individuals with a LOS of 10 days or less were included that were alive at discharge $(N=159,924)$. Outcome included death from day 11 to days 30 after admission, and LOS was included as an explanatory variable (non-time dependent) together with the other covariates. In the model including all covariates, the strongest risk factors $\left(P<1 \times 10^{-25}\right.$ for all $)$ for 30-day mortality included LOS (HR, 0.91, 95\% CI, 0.91-0.92, per day longer LOS), age (HR, $1.08,95 \%$ CI, 1.07-1.08, per day higher age), and female sex (HR, 0.46, 95\% CI, 0.44-0.49).

\section{Discussion}

This nationwide study showed that both the incidence and the total number of hip fractures decreased in Sweden between 1998 and 2017, despite a concurrent aging of the population. In contrast, 30-day mortality after admission increased in both women and men. Strong risk factors for higher mortality included older age, male sex, and LOS which decreased with 4 days during the study period. Possibly, the fact that LOS was not adapted to these risk factors may have influenced the increase in short-term mortality that was observed during the study period.

The result of the present study contradicts projections which suggest that hip fractures will become more common in the future [13, 14], but are supported by recent studies from high-income countries [16-18, 25]. In our population, there was no sign for this decreasing trend to level off, which is of great interest with respect to other populations around the world where the number of older people is also increasing. Any reasons for the declining number of fractures in our nationwide cohort would be of interest to evaluate. We found no evidence of an increased use of bone-specific agents during the last decade in Sweden, a pattern which appears similar to that observed in other countries [26]. It could also be argued that the decreasing incidence of hip fractures may 


\section{(A) Women}

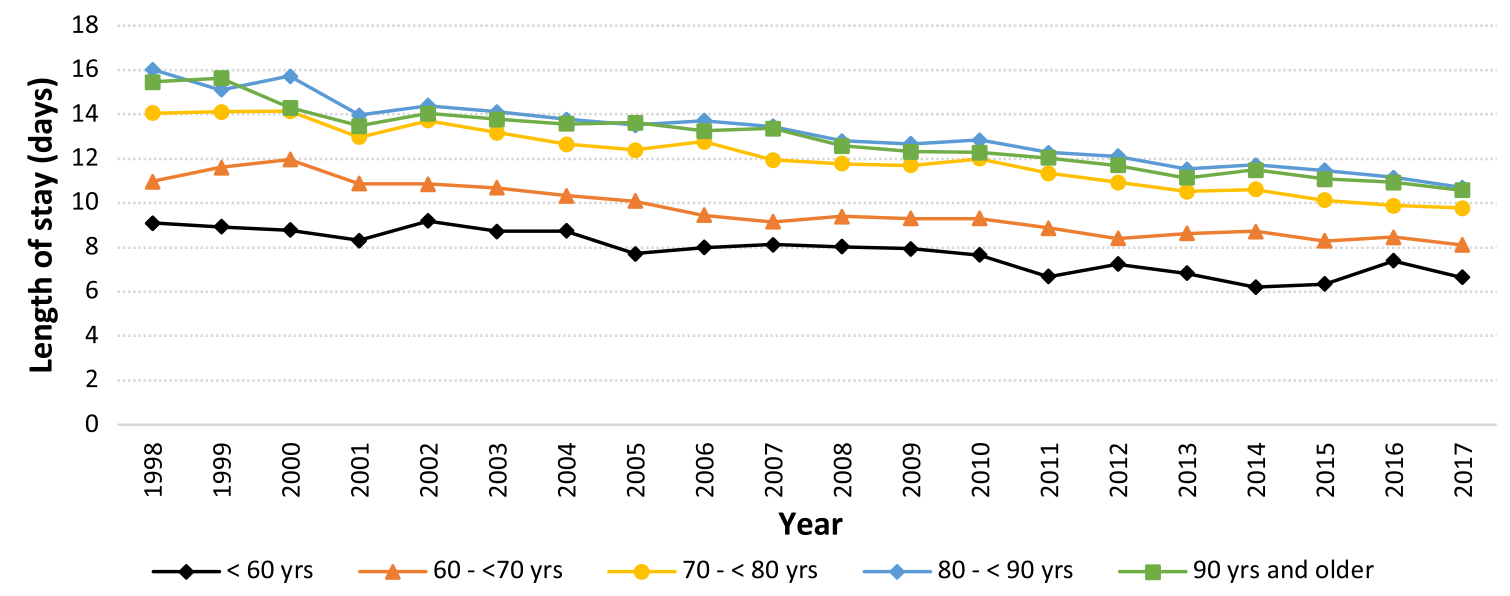

(B) Men

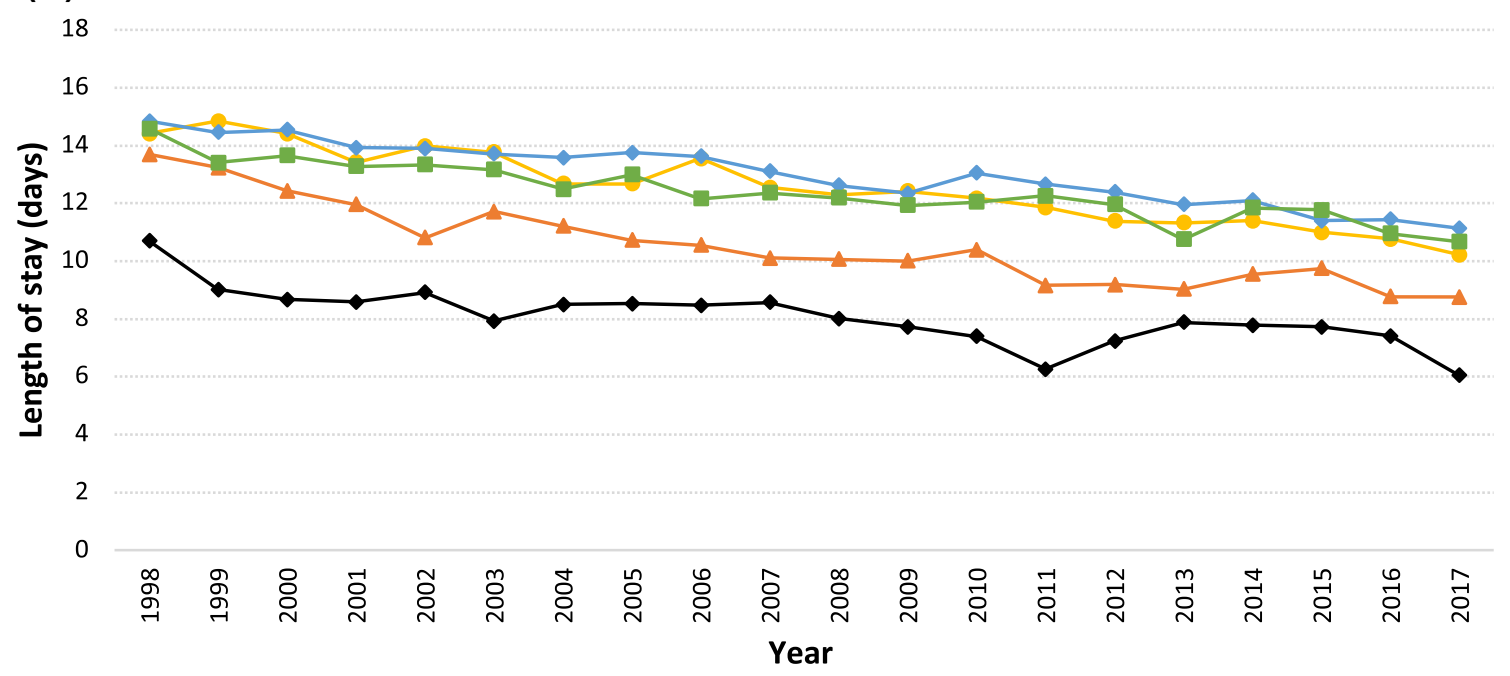

Fig. 3 Inpatient length of stay in female hip fracture patients (A) and in male hip fracture patients (B) from 1998 to 2017 according to age groups

relate to climate change, resulting in less snow and ice. However, less than $4 \%$ of all hip fractures were diagnosed as due to snow and ice, suggesting that also this explanation is unlikely. Other factors, such a decreased use of tobacco, $[25,27]$ unexpected potential protective effects of commonly used drugs [28, 29], or a lower burden of concomitant disease, all of which reflect a healthier aging, may have influenced the hip fracture incidence in our study. Indeed, according to annual investigations by the Public Health Agency of Sweden, self-reported smoking decreased from 13\% to 7\% in the Swedish population between 2006 and 2020 [30]. In our cohort there was also a decreasing prevalence of concomitant cardiovascular disease during follow-up, further supporting a healthier aging.

During follow-up, 30-day mortality increased in both men and women. This observation stands in contrast to the decreased mortality seen in other large non-communicable diseases, such as myocardial infarction [31]. The increased 30-day mortality also stands in contrast to a study from the US, where age- and risk-adjusted mortality after hip fracture was slightly reduced between 1985 and 2005 [12], Although these data are older, it is also of interest that LOS was reduced to half during the study period, and that another more recent study from the US found no association between shorter LOS and mortality in hip fracture patients [32]. Furthermore, in a study from the UK, 30-day mortality after hip fracture decreased from 12 to $6 \%$ between 2006 and 2012 [33]. Thus, the opposite trend observed in Sweden is clearly a cause of concern. In a recent study, using a similar cohort from Sweden, mortality remained rather constant, and was somewhat improved during the years of follow-up when adjusted for Charlson comorbidity index [18]. The different covariates used compared to in our study may explain the somewhat different results. In our nationwide cohort, 
higher 30-day mortality was predominantly explained by higher age, male sex, and a shorter inpatient LOS during follow-up. Because hip fracture patients are generally frail, have multimorbidity, and are at high risk of complications and ultimately death $[4,34,35]$, it seems rather clear that LOS should be adapted to each patient's individual risk factors. However, we noted that LOS was similar in women and men, and shorter in patients aged at least 90 years of age, compared to those aged 80-89 years of age. If the relationship is causal, it is possible that the shorter LOS may have influenced mortality during the study period, which was highest in men aged 90 and above, and also increased most in this frail patient group during the study period.

The present study has limitations that should be considered. First, although hospitals are staffed by highly experienced and educated personnel, the observational design of this study means that we cannot precisely determine to which extent a longer LOS would reduce 30-day mortality, for example in frail men aged 90 and above. Second, we lacked certain covariates of importance, such as an adequate measure of the patient's health status at admission, which may have changed during the study period, as well as data on type of hospital and post-anesthesia care unit LOS, which may influence the 30-day mortality estimates [36, 37]. Third, there were some interesting observations with respect to trends in operation techniques, such as a shift toward use of intramedullary nails for intertrochanteric fractures and toward prosthesis for femoral neck fractures. However, we were unable to investigate associations between these trends and the risk of short-term mortality or disability due to the lack of certain important covariates such as patient's health status at admission and follow-up data on mobility. This remains an area for future investigation. Fourth, reliable data on cause-specific deaths are not available from Swedish national registers. Yet, for the outcome 30-day mortality after a hip fracture, the operation and fracture are generally regarded as strong contributing causes of death, with complications including infection and cardiovascular disease [38, $39]$. The strengths of the study include the long study duration of 20 years, the use of national registers, which ensured complete coverage of all hip fractures in Sweden and no loss to follow-up for 30-day mortality, altogether increasing the external and internal validity of the study results.

In summary, during the past 20 years, both the number and incidence of hip fractures in Sweden has decreased, despite the aging of the population. Possibly, this trend may partly be explained by favorable changes in the prevalence of smoking and concomitant disease in older people. In contrast, 30-day mortality increased during the study period, where higher mortality was predominantly associated with male sex, higher age, and shorter LOS, the latter which also decreased during the study period. With the limitation of being an observational study, these results indicate that shortening LOS may potentially have a detrimental impact on the risk of subsequent complications and death in frail patients with hip fracture.

Supplementary Information The online version contains supplementary material available at https://doi.org/10.1007/s00223-022-00954-4.

Author Contributions PN and JB conceived and designed the study. PN acquired the data. PN and JB analyzed the data. All authors interpreted the data. PN drafted the manuscript. All authors revised the work critically for important intellectual content. All authors gave final approval of the version to be published. All authors agree to be accountable for all aspects of the work in ensuring that questions related to the accuracy or integrity of any part of the work are appropriately investigated and resolved.

Funding Open access funding provided by Umea University. The present study was not funded.

\section{Declarations}

Conflict of Interest Peter Nordström, Jonathan Bergman, Marcel Ballin, and Anna Nordström declare that they have no conflict of interest.

Human and Animal Rights This study was approved by the Swedish Ethical Review Authority (number 2019-04765), by the National Board of Health and Welfare, and by Statistics Sweden. The study was performed in accordance with the ethical standards as laid down in the Declaration of Helsinki.

Informed Consent The Swedish Ethical Review Authority waived the requirement of obtaining informed consent given the retrospective study design.

Open Access This article is licensed under a Creative Commons Attribution 4.0 International License, which permits use, sharing, adaptation, distribution and reproduction in any medium or format, as long as you give appropriate credit to the original author(s) and the source, provide a link to the Creative Commons licence, and indicate if changes were made. The images or other third party material in this article are included in the article's Creative Commons licence, unless indicated otherwise in a credit line to the material. If material is not included in the article's Creative Commons licence and your intended use is not permitted by statutory regulation or exceeds the permitted use, you will need to obtain permission directly from the copyright holder. To view a copy of this licence, visit http://creativecommons.org/licenses/by/4.0/.

\section{References}

1. Johnell O, Kanis JA (2006) An estimate of the worldwide prevalence and disability associated with osteoporotic fractures. Osteoporos Int 17(12):1726-1733

2. Svensson HK, Olofsson EH, Karlsson J, Hansson T, Olsson LE (2016) A painful, never ending story: older women's experiences of living with an osteoporotic vertebral compression fracture. Osteoporos Int 27(5):1729-1736

3. Michaelsson K, Nordstrom P, Nordstrom A, Garmo H, Byberg L, Pedersen NL, Melhus H (2014) Impact of hip fracture on mortality: a cohort study in hip fracture discordant identical twins. J Bone Miner Res 29(2):424-431 
4. Haentjens P, Magaziner J, Colon-Emeric CS, Vanderschueren D, Milisen K, Velkeniers B, Boonen S (2010) Meta-analysis: excess mortality after hip fracture among older women and men. Ann Intern Med 152(6):380-390

5. Center JR, Nguyen TV, Schneider D, Sambrook PN, Eisman JA (1999) Mortality after all major types of osteoporotic fracture in men and women: an observational study. Lancet 353(9156):878-882

6. Nordstrom P, Gustafson Y, Michaelsson K, Nordstrom A (2015) Length of hospital stay after hip fracture and short term risk of death after discharge: a total cohort study in Sweden. BMJ 350:h696

7. Abrahamsen B, van Staa T, Ariely R, Olson M, Cooper C (2009) Excess mortality following hip fracture: a systematic epidemiological review. Osteoporos Int 20(10):1633-1650

8. Tang VL, Sudore R, Cenzer IS, Boscardin WJ, Smith A, Ritchie C, Wallhagen M, Finlayson E, Petrillo L, Covinsky K (2017) Rates of recovery to pre-fracture function in older persons with hip fracture: an observational study. J Gen Intern Med 32(2):153-158

9. Nilson F, Moniruzzaman S, Gustavsson J, Andersson R (2013) Trends in hip fracture incidence rates among the elderly in Sweden 1987-2009. J Public Health (Oxf) 35(1):125-131

10. Karampampa K, Ahlbom A, Michaelsson K, Andersson T, Drefahl S, Modig K (2015) Declining incidence trends for hip fractures have not been accompanied by improvements in lifetime risk or post-fracture survival-A nationwide study of the Swedish population 60 years and older. Bone 78:55-61

11. Dhanwal DK, Dennison EM, Harvey NC, Cooper C (2011) Epidemiology of hip fracture: worldwide geographic variation. Indian $\mathrm{J}$ Orthop 45(1):15-22

12. Brauer CA, Coca-Perraillon M, Cutler DM, Rosen AB (2009) Incidence and mortality of hip fractures in the United States. JAMA 302(14):1573-1579

13. United Nations. World Population Aging: 1950-2050. [Cited April 5, 2018]. Available at: http://www.un.org/esa/population/ publications/worldageing 19502050/.

14. Kannus P, Niemi S, Parkkari J, Palvanen M, Vuori I, Jarvinen M (1999) Hip fractures in Finland between 1970 and 1997 and predictions for the future. Lancet 353(9155):802-805

15. Tamaki J, Fujimori K, Ikehara S, Kamiya K, Nakatoh S, Okimoto N, Ogawa S, Ishii S, Iki M (2019) Working Group of Japan Osteoporosis F: estimates of hip fracture incidence in Japan using the National Health Insurance Claim Database in 2012-2015. Osteoporos Int 30(5):975-983

16. Lewiecki EM, Wright NC, Curtis JR, Siris E, Gagel RF, Saag KG, Singer AJ, Steven PM, Adler RA (2018) Hip fracture trends in the United States, 2002 to 2015. Osteoporos Int 29(3):717-722

17. Abrahamsen B, Skjodt MK, Vestergaard P (2019) Hip fracture rates and time trends in use of anti-osteoporosis medications in Denmark for the period 2005 to 2015: missed opportunities in fracture prevention. Bone 120:476-481

18. Meyer AC, Ek S, Drefahl S, Ahlbom A, Hedstrom M, Modig K (2021) Trends in hip fracture incidence, recurrence, and survival by education and comorbidity: a Swedish register-based study. Epidemiology 32(3):425-433

19. Compston JE, McClung MR, Leslie WD (2019) Osteoporosis. Lancet 393(10169):364-376

20. Ballane G, Cauley JA, Luckey MM, Fuleihan Gel H (2014) Secular trends in hip fractures worldwide: opposing trends East versus West. J Bone Miner Res 29(8):1745-1755

21. Qureshi A, Gwyn Seymour D (2003) Growing knowledge about hip fracture in older people. Age Ageing 32(1):8-9

22. Lavikainen P, Koponen M, Taipale H, Tanskanen A, Tiihonen J, Hartikainen S, Tolppanen AM (2020) Length of hospital stay for hip fracture and 30-day mortality in people with Alzheimer's disease: a cohort study in Finland. J Gerontol A Biol Sci Med Sci 75(11):2184-2192
23. The Statistics Sweden Database. Official population statistics. Sweden. Accessed 20 Dec 2020.

24. Brooke HL, Talbäck M, Hörnblad J, Johansson LA, Ludvigsson JF, Druid H, Feychting M, Ljung R (2017) The Swedish cause of death register. Eur J Epidemiol 32(9):765-773

25. Swayambunathan J, Dasgupta A, Rosenberg PS, Hannan MT, Kiel DP, Bhattacharyya T (2020) Incidence of hip fracture over 4 decades in the framingham heart study. JAMA Intern Med 180(9):1225-1231

26. Jha S, Wang Z, Laucis N, Bhattacharyya T (2015) Trends in media reports, oral bisphosphonate prescriptions, and hip fractures 1996-2012: an ecological analysis. J Bone Miner Res 30(12):2179-2187

27. Kanis JA, Johnell O, Oden A, Johansson H, De Laet C, Eisman JA, Fujiwara S, Kroger H, McCloskey EV, Mellstrom D et al (2005) Smoking and fracture risk: a meta-analysis. Osteoporos Int 16(2):155-162

28. Bauer DC, Mundy GR, Jamal SA, Black DM, Cauley JA, Ensrud KE, van der Klift M, Pols HA (2004) Use of statins and fracture: results of 4 prospective studies and cumulative meta-analysis of observational studies and controlled trials. Arch Intern Med 164(2):146-152

29. Schoofs MW, van der Klift M, Hofman A, de Laet CE, Herings RM, Stijnen T, Pols HA, Stricker BH (2003) Thiazide diuretics and the risk for hip fracture. Ann Intern Med 139(6):476-482

30. Publlc health agency of Sweden. Annual reports of use of tobacco. https://www.folkhalsomyndigheten.se/folkhalsorapportering-stati stik/tolkad-rapportering/folkhalsans-utveckling/resultat/levna dsvanor/tobaksrokning-daglig/. [Cited March 1].

31. Johansson S, Rosengren A, Young K, Jennings E (2017) Mortality and morbidity trends after the first year in survivors of acute myocardial infarction: a systematic review. BMC Cardiovasc Disord 17(1):53

32. Nikkel LE, Kates SL, Schreck M, Maceroli M, Mahmood B, Elfar JC (2015) Length of hospital stay after hip fracture and risk of early mortality after discharge in New York state: retrospective cohort study. BMJ 351:h6246

33. Chatterton BD, Moores TS, Ahmad S, Cattell A, Roberts PJ (2015) Cause of death and factors associated with early in-hospital mortality after hip fracture. Bone Joint J 97-B(2):246-251

34. Lawrence VA, Hilsenbeck SG, Noveck H, Poses RM, Carson JL (2002) Medical complications and outcomes after hip fracture repair. Arch Intern Med 162(18):2053-2057

35. Roche JJ, Wenn RT, Sahota O, Moran CG (2005) Effect of comorbidities and postoperative complications on mortality after hip fracture in elderly people: prospective observational cohort study. BMJ 331(7529): 1374

36. Ahman R, Siverhall PF, Snygg J, Fredrikson M, Enlund G, Bjornstrom K, Chew MS (2018) Determinants of mortality after hip fracture surgery in Sweden: a registry-based retrospective cohort study. Sci Rep 8(1): 15695

37. Gremillet C, Jakobsson JG (2018) Acute hip fracture surgery anaesthetic technique and 30-day mortality in Sweden 2016 and 2017: a retrospective register study. F1000Res 7:1009

38. Sheikh HQ, Hossain FS, Aqil A, Akinbamijo B, Mushtaq V, Kapoor H (2017) A comprehensive analysis of the causes and predictors of 30-day mortality following hip fracture surgery. Clin Orthop Surg 9(1):10-18

39. Blanco JF, da Casa C, Pablos-Hernandez C, Gonzalez-Ramirez A, Julian-Enriquez JM, Diaz-Alvarez A (2021) 30-day mortality after hip fracture surgery: influence of postoperative factors. PLoS One 16(2):e0246963

Publisher's Note Springer Nature remains neutral with regard to jurisdictional claims in published maps and institutional affiliations. 